\title{
Activity of cesium-137 in fruiting bodies of species of the genus Leccinum in the vicinity of the Seytesyavr Lake (Khibiny)
}

\author{
Dmitriy Ivanov ${ }^{1, *}$ and Evgeniy Ivanov ${ }^{2}$ \\ ${ }^{1}$ Saint Petersburg State University of Civil Aviation, Saint-Petersburg, Pilots str., 38, 196210, Russia \\ ${ }^{2}$ Saint Petersburg State University, Saint-Petersburg, University embankment, 7/9, 199034, Russia
}

\begin{abstract}
Analysis of the specific activity of cesium-137 in the fruiting bodies of representatives of the genus Leccinum collected during mass fruiting in the vicinity of the Seytesyavr Lake (Khibiny) showed that it does not exceed the permissible values. The data obtained can be used as reference data for comparison with the results of accumulation of cesium137 by fruiting bodies of species of the genus Leccinum collected in other regions.
\end{abstract}

\section{Introduction}

The destruction of the fourth power unit of the Chernobyl nuclear power plant on April 26, 1986 led to the global spread of a number of isotopes, including cesium-137 [1]. This isotope does not occur in nature. It spreads in the environment during accidents at nuclear power facilities [2] and tests of atomic weapons. Cesium-137 has widely spread throughout Europe. Forest and bog ecosystems suffered the most [3]. One of the characteristics of pollution is its mosaic pattern, when places with and without exceeding the permissible values are adjacent to each other.

Living organisms absorb cesium-137 as an analogue of potassium, which, thanks to the sodium-potassium pump of cell membranes, creates a certain potential difference that plays a key role in the functioning of living organisms. Mushrooms are one of the most absorbing cesium-137 groups of living organisms [4, 5], which, according to the principle of their nutrition, are ectomycorrhizal, which are in obligate connection with the roots of the main forest-forming tree species, such as spruce, pine, birch and aspen.

We were the first to establish that among the ecological and trophic group of ectomycorrhizal fungi, there are species that change the morphological characteristics of the hymenial layer in response to the accumulation of cesium-137 by fruiting bodies [6]. They belong to the representatives of the genus Leccinum, which unites aspen mushrooms and birch mushrooms. These mushrooms are popular among the population of Russia as an object of mushroom hunting and a gastronomic dish, since the collection of wild-growing edible mushrooms and their consumption are part of the national culture.

\footnotetext{
*Corresponding author: lusis63@mail.ru
} 
With the use of species of the genus Leccinum, monitoring of forest and bog ecosystems in the Leningrad region was carried out, as a result of which it was found that on raised bogs and in swampy forests with the participation of green mosses, conditions are created for the accumulation of cesium-137 by the fruiting bodies of mushrooms, the activity in which exceeds the permissible values [7].

The choice of the territory of the Murmansk region and the Khibiny mountain range as a place for conducting research was caused by the following facts. Although the territory of the Murmansk region is closer to the former nuclear weapons test site on Novaya Zemlya, nevertheless, there are no pollution zones on its territory that arose as a result of the passage of the Chernobyl trail. While in the Leningrad region, there are zones of pollution with a density of $1 \mathrm{Ci} / \mathrm{km}^{2}$, the activity in the area of the Khibiny massif does not exceed $0.10-0.15$ $\mathrm{Ci} / \mathrm{km}^{2}$.

In addition, the uniqueness of the Khibiny ecosystems lies in the fact that in a small area, due to the high-altitude zonality, natural zones of northern taiga forests, forest-tundra and tundra are adjacent to each other. This combination of conditions affects the diversity of morphological forms of the species of the genus Leccinum under study, which was noted in the works of the classic of Russian mycology B.P. Vasilkov [8].

The aim of this work was to assess the activity of cesium-137 in the fruiting bodies of mushrooms of the genus Leccinum, collected as a result of their mass fruiting, found near the Seytesyavr Lake.

\section{Research materials and methods}

The collection of the fruiting bodies of mushrooms was carried out on July 29, 2013 along the route running from the dirt road leading to the quarry, across the plateau, at the southern tip of the Poachvumchorr ridge with a descent to the southern shore of the lake, further from the spring along the western shore of the Seytesyavr Lake. Further, the collection was carried out between the tourist trail and the bank of an unnamed stream, which originates in the Seytesyavr Lake and flows into the Maly Vudyavr Lake, where the route was completed. The route coordinates (Table 1) were determined using an etrex navigator manufactured by Garmin.

Table 1. Coordinates of the route for collecting fruiting bodies of mushrooms.

\begin{tabular}{|c|c|c|c|c|}
\hline No. & Legend.* & GPS coordinates & S, $\mathbf{m}^{* *}$ & $\mathbf{S}, \mathbf{\Sigma} \mathbf{~ m}^{* * *}$ \\
\hline 1. & 446 & $\left(\mathrm{~N} 67^{\circ} 40.681^{\prime}, \mathrm{E} 033^{\circ} 39.258^{\prime}, \mathrm{H} 396 \mathrm{~m}\right)$ & 0 & 0 \\
\hline 2. & 447 & $\left(\mathrm{~N} 67^{\circ} 40.663^{\prime}, \mathrm{E} 033^{\circ} 39.075^{\prime}, \mathrm{H} 412 \mathrm{~m}\right)$ & 133 & 133 \\
\hline 3. & 448 & $\left(\mathrm{~N} 67^{\circ} 40.414^{\prime}, \mathrm{E} 033^{\circ} 39.054^{\prime}, \mathrm{H} 388 \mathrm{~m}\right)$ & 462 & 592 \\
\hline 4. & 449 & $\left(\mathrm{~N} 67^{\circ} 40.331^{\prime}, \mathrm{E} 033^{\circ} 38.976^{\prime}, \mathrm{H} 394 \mathrm{~m}\right)$ & 164 & 759 \\
\hline 5 & 450 & $\left(\mathrm{~N} 67^{\circ} 40.320^{\prime}, \mathrm{E} 033^{\circ} 38.780^{\prime}, \mathrm{H} 372 \mathrm{~m}\right)$ & 139 & 898 \\
\hline 6. & 451 & $\left(\mathrm{~N} 67^{\circ} 40.292^{\prime}, \mathrm{E} 033^{\circ} 38.706^{\prime}, \mathrm{H} 381 \mathrm{~m}\right)$ & 74 & 972 \\
\hline 7. & 452 & $\left(\mathrm{~N} 67^{\circ} 40.243^{\prime}, \mathrm{E} 033^{\circ} 38.592^{\prime}, \mathrm{H} 381 \mathrm{~m}\right)$ & 121 & 1093 \\
\hline 8. & 445 & $\left(\mathrm{~N} 67^{\circ} 40.177^{\prime}, \mathrm{E} 033^{\circ} 38.553^{\prime}, \mathrm{H} 370 \mathrm{~m}\right)$ & 127 & 1200 \\
\hline
\end{tabular}

Note: * - No. GPS coordinate in the device; ** S - distance to previous point; ***route length.

The route is plotted on the diagram shown in Fig. 1, compiled on the basis of a satellite $\operatorname{map}[9]$. 


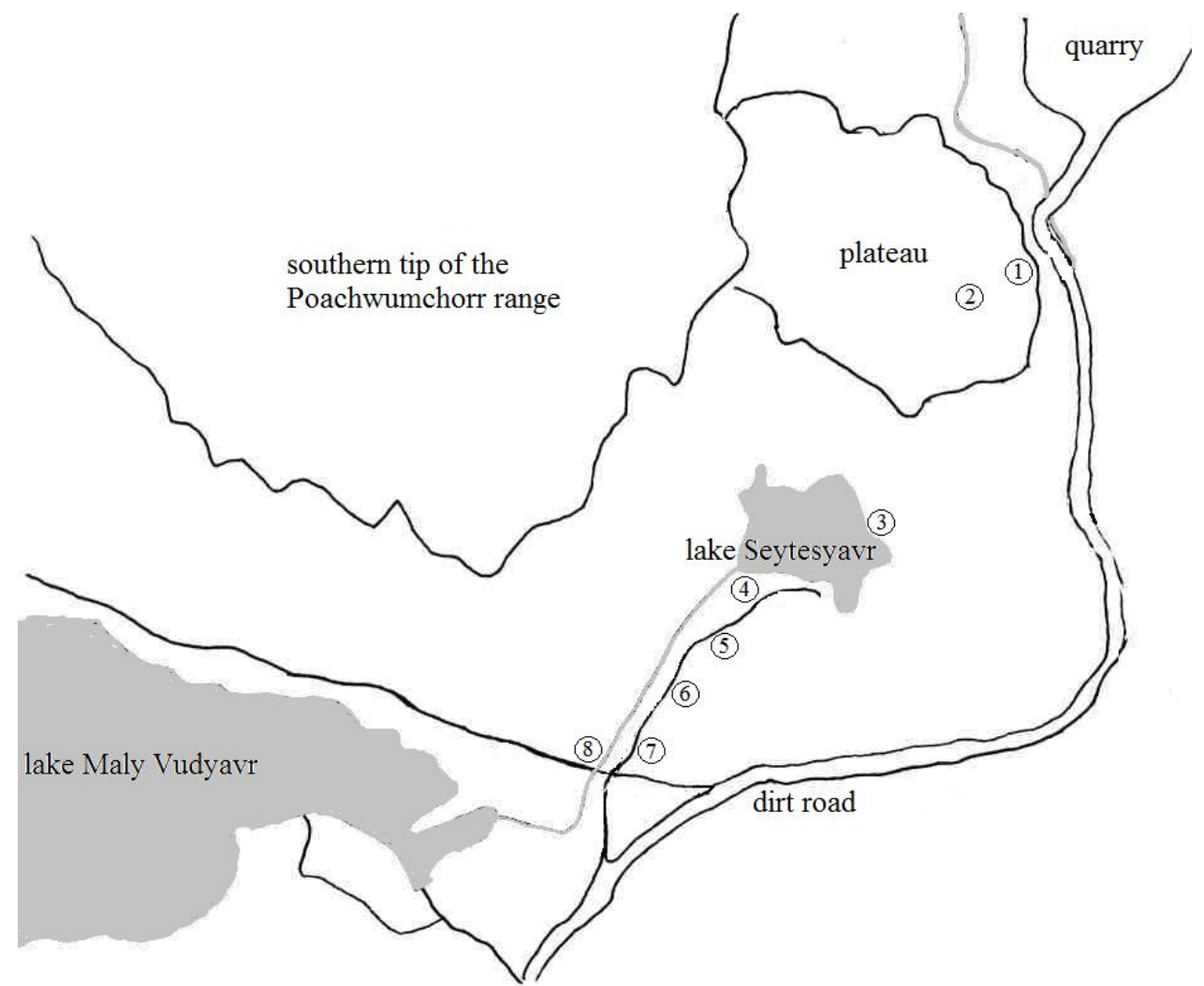

Fig. 1. Scheme of the route for collecting fruiting bodies of mushrooms.

Before collecting the fruiting body, it was photographed; thumbnails of photographs are shown in Fig. 2.

Office studies of the collected fruiting bodies were carried out. The diameter of the cap $\mathrm{D}_{\text {cap }}, \mathrm{cm}$ and the height of the mushroom $\mathrm{H}, \mathrm{cm}$ were measured (Table 2). Appropriate entries were made on the labels accompanying the samples. Fresh fruit bodies were cut into $1 \mathrm{~cm}$ thick plates, which were then dried in a stream of warm air using an electric dryer "Sukhovey" at a temperature of $40^{\circ} \mathrm{C}$ to an air-dry weight and packed in herbarium envelopes.

The activity was measured using a Beta radiometer, and the radionuclide composition of the samples was determined using an MKGB-01 RADEK gamma-spectrometer manufactured by the Radiation Ecology Research Center. 

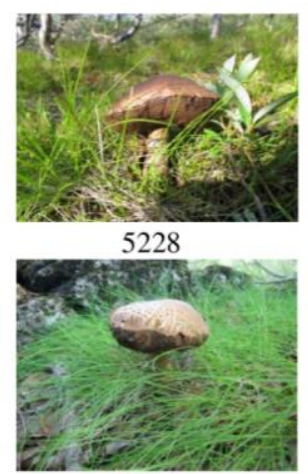

5255

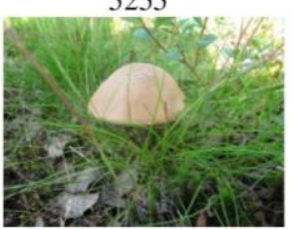

5281

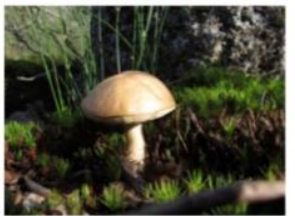

5305

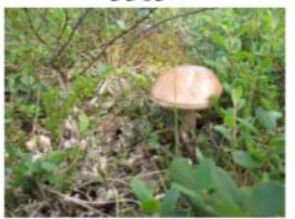

5386

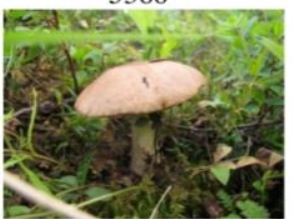

5404

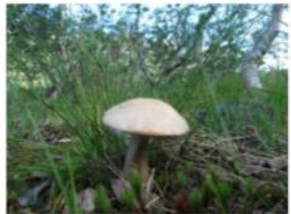

5234

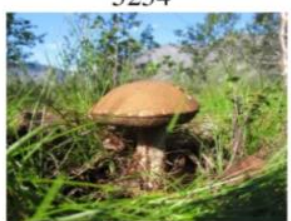

5259

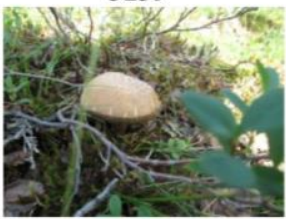

5283

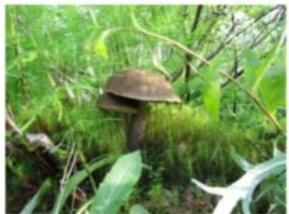

5334

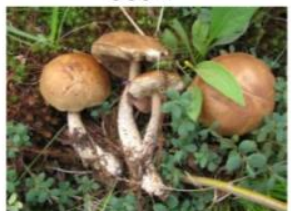

5396

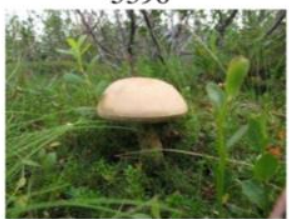

5406

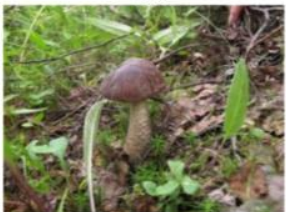

5433

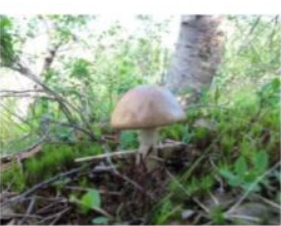

5240

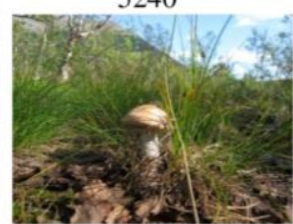

5266

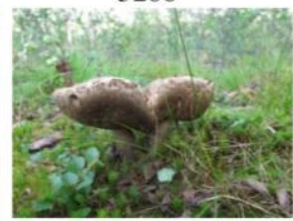

5293

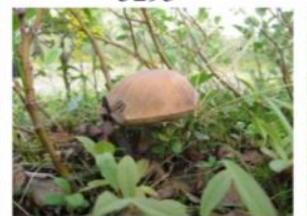

5381

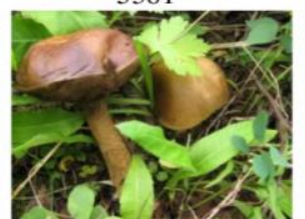

5398

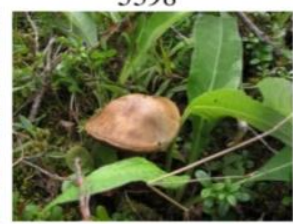

5413

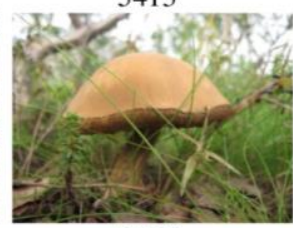

5435

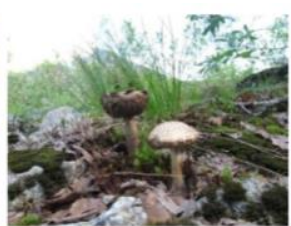

5250

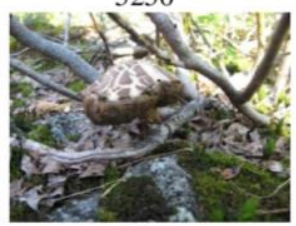

5271

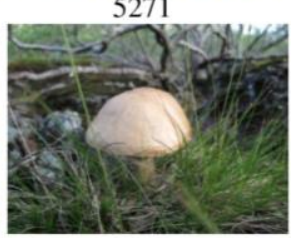

5302

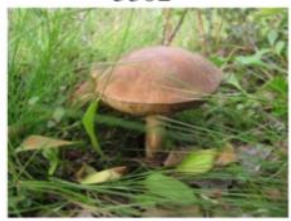

5385

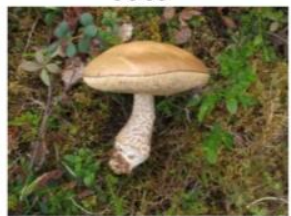

5400

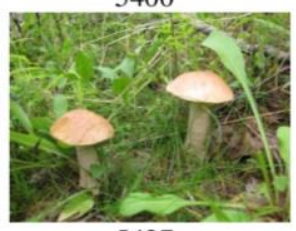

5427

Fig. 2. Thumbnails of photographs of fruiting bodies of mushrooms used to measure specific activity.

\section{Results and their discussion}

It should be noted that the question of the species belonging of the studied fruiting bodies has not been finally resolved. In the article [8], on the basis of morphological and microscopic data, fruiting bodies with morphological characteristics of the mushrooms 
studied in this work were assigned to the species Leccinum rotundifoliae (Singer) A.H. Sm., Thiers \& Watling. According to the results of the analysis of the region of ribosomal DNA of the fruiting bodies of mushrooms collected by the authors in the region of the Khibiny mountain range in 2006, in other places, most of the fruiting bodies with a brown and gray caps were attributed to the species Leccinum scabrum (Bull.: Fr.) S.F. Gray [6]. Nevertheless, the question of the species belonging of such samples has not been finally resolved, but requires further studies, since according to the article [10], there are indications that interspecific hybridization may occur between species of the genus Leccinum. For the fruiting bodies of the mushrooms used in this work, DNA analysis has not yet been carried out, and the species name Leccinum scabrum should be understood as technical, which can later be clarified.

A comment should be made regarding route selection and terrain. The beginning of the route is the place where the first fruiting bodies of the species of the genus Leccinum were discovered. Further, the route was determined by the discovery of the following places of mass fruiting of mushrooms.

Despite the fact that the fruiting of the vegetative mycelium of mushrooms is sporadic, and the identification of many patterns of such fruiting requires further research, the laying of the route on the ground is not accidental. It is caused by the result of a systematic survey of extended territories by the route method to detect places of mass fruiting of mushrooms, which, according to the figurative expression of B.P. Vasilkov, are called "mushroom places" [11].

During the survey of the surroundings of the Khibiny mountain range on July 27-29, 2013 to detect the fruiting of mushrooms, the places where such fruiting was observed earlier during the previous collection of mushrooms in 2006 [12] were surveyed by the route method. However, only single fruiting bodies were found in these places. It was noted that the dryness of the soil due to the lack of precipitation during the growing season led to the fact that fruiting was found in a new place and nearby water sources, such as an unnamed stream flowing from the Seytesyavr Lake and flowing into the Maly Vudyavr Lake. In addition, fruiting bodies were found on the southern shore of the Seytesyavr Lake near a spring and in depressions on a small plateau at the southern foot of the Poachvumchorr ridge stretched from north to south, to which ecosystems formed with the participation of mountain birch are confined.

It should be noted that for monitoring fruiting, this route was passed on August 7, 2018, but only one fruiting body was found. These facts indicate the uniqueness of each mass collection of material similar to July 29, 2013 and the need to use it both for monitoring the radiation situation in the studied area and for comparison with the results obtained in other regions.

To measure the activity, only the caps of the fruit bodies were used, since the activity in the stems is 3-4 times lower than in the caps [13]. It should be taken into account that on the lower surface of the cap of the fruiting body of the mushrooms, there is a hymenial tubular layer, which is the place of karyogamy and the formation of haploid spores. It is a known fact that in living organisms, the structures responsible for the course of the reproductive process accumulate radionuclides mainly due to intensive metabolic processes.

Activity measurements were carried out in samples of mushroom fruiting bodies dried to an air-dry weight. Measurements are not carried out in fresh fruiting bodies, since the range of beta particles in wet objects is insignificant and does not allow correct detection. As a result of the verification of the measurement technique in the fruiting bodies of mushrooms, the percentage of dry matter was checked using the example of Leccinum holopus (Rostk.) Watling, which was $9.8 \pm 0.8 \%$ of the weight of fresh fruiting bodies [14]. 
In Table 2, as one of the characteristics of the measured sample, the air-dry mass of the entire cap of the fruiting body is shown. It has been established that this is a tenth of the mass of a fresh cap. These values allow discussing two aspects related to the possibility of analyzing ecosystems formed with the participation of tree species and ectomyocrisforming mushrooms.

The data on the mass of fruiting bodies make it possible to characterize the productivity of the ecosystem. All collected fruiting bodies are small in size, which, when dried, give such a sample.

The values of the mass of the cap of the fruiting bodies are close to the values obtained for the fruiting bodies formed under the conditions of the raised bogs of the Leningrad region, which are also characterized by low productivity [7].

In relation to the activity of cesium-137 in the soil, there is a tenfold concentration of the radionuclide by the fruiting bodies of the mushrooms of the studied genus, which is characterized by the corresponding accumulation coefficients. Selective concentration of cesium-137 by fruiting bodies of mushrooms from the soil is an argument for their use as objects for monitoring the radiation situation.

The results of the analysis of the specific activity of cesium-137 in the fruiting bodies of mushrooms are shown in table 2.

Table 2. Specific activity of cesium-137 in fruiting bodies.

\begin{tabular}{|l|l|c|c|c|c|c|}
\hline No. & Species & Photo No.**** & $\mathbf{H}, \mathbf{c m}^{* * * *}$ & $\mathbf{D}_{\text {cap }} \mathbf{c m}^{* * *}$ & $\mathbf{m}_{\text {cap }}, \mathbf{g}^{* *}$ & $\mathbf{Q}_{ \pm \Delta \mathbf{\Delta}} * \mathbf{B q} \mathbf{k g}$ \\
\hline 1. & L. scabrum & 5228 & 12.5 & 8.0 & 5.00 & $1260 \pm 108$ \\
\hline 2. & L. scabrum & 5234 & 7.5 & 5.5 & 1.90 & $1419 \pm 131$ \\
\hline 3. & L. scabrum & 5240 & 6.0 & 4.5 & 1.40 & $1479 \pm 87$ \\
\hline 4. & L. scabrum & 525011 & 10.0 & 5.0 & 4.30 & $989 \pm 80$ \\
\hline 5. & L. scabrum & 525021 & 8.0 & 4.0 & 1.70 & $1042 \pm 120$ \\
\hline 6. & L. scabrum & 5255 & 11.0 & 5.0 & 4.10 & $1157 \pm 45$ \\
\hline 7. & L. scabrum & 5259 & 9.0 & 8.0 & 5.00 & $1256 \pm 60$ \\
\hline 8. & L. scabrum & 5266 & 8.0 & 4.0 & 1.60 & $1430 \pm 146$ \\
\hline 9. & L. scabrum & 5271 & 9.5 & 6.0 & 5.20 & $784 \pm 45$ \\
\hline 10. & L. scabrum & 5281 & 9.0 & 5.5 & 3.15 & $1354 \pm 97$ \\
\hline 11. & L. scabrum & 5283 & 8.5 & 4.5 & 2.60 & $954 \pm 100$ \\
\hline 12. & L. scabrum & 5293 & 7.0 & 8.0 & 4.00 & $1143 \pm 90$ \\
\hline 13. & L. scabrum & 5302 & 9.0 & 8.0 & 1.45 & $1643 \pm 191$ \\
\hline 14. & L. scabrum & 5305 & 7.5 & 4.5 & 1.25 & $1906 \pm 216$ \\
\hline 15. & L. scabrum & 5334 & 14.5 & 6.5 & 2.45 & $1339 \pm 102$ \\
\hline 16. & L. scabrum & 5381 & 13.0 & 7.5 & 3.75 & $1478 \pm 92$ \\
\hline 17. & L. scabrum & 5385 & 12.0 & 7.0 & 3.20 & $1669 \pm 72$ \\
\hline 18. & L. scabrum & 5386 & 14.0 & 7.0 & 4.00 & $1503 \pm 75$ \\
\hline 19. & L. scabrum & 539611 & 11.0 & 8.0 & 2.30 & $1659 \pm 96$ \\
\hline 20. & L. scabrum & 539621 & 14.0 & 8.0 & 3.00 & $1653 \pm 97$ \\
\hline 21. & L. scabrum & 539631 & 11.0 & 5.0 & 1.90 & $1163 \pm 192$ \\
\hline 22. & L. scabrum & 539641 & 12.5 & 8.0 & 5.00 & $1270 \pm 33$ \\
\hline 23. & L. scabrum & 539821 & 11.0 & 8.0 & 4.10 & $1304 \pm 70$ \\
\hline 24. & L. scabrum & 5400 & 10.0 & 9.5 & 5.00 & $1185 \pm 38$ \\
\hline 25. & L. scabrum & 5404 & 12.0 & 8.5 & 3.40 & $1776 \pm 95$ \\
\hline 26. & L. scabrum & 5406 & 9.0 & 6.0 & 2.70 & $1822 \pm 71$ \\
\hline 27. & L. scabrum & 5413 & 9.5 & 6.5 & 3.10 & $1643 \pm 107$ \\
\hline 28. & L. scabrum & 5427 & 14.0 & 6.0 & 3.40 & $1419 \pm 95$ \\
\hline 29. & L. scabrum & 5433 & 13.0 & 5.0 & 1.90 & $1520 \pm 102$ \\
\hline 30. & L. scabrum & 5435 & 13.0 & 8.5 & 3.20 & $1329 \pm 118$ \\
\hline
\end{tabular}

Note: 
* - the confidence interval of the average activity is given at the significance level $\mathrm{p}<0.05$;

$\mathrm{m}_{\text {cap }}, \mathrm{g}^{* *}$ air-dry mass of the cap of the fruiting body of the mushroom;

$\mathrm{H}, \mathrm{cm}^{* * *}$ the height of the fruiting body of the mushroom from the base of the stem to the top of the cap;

$\mathrm{D}_{\text {cap }}, \mathrm{cm}^{* * * *}$ diameter of the cap measured along the line passing along the hymenial layer of the lower surface of the cap through the center of the stem;

Photo No.***** if there are several fruiting bodies in the photo, then additional numbering is on the left.

\section{Discussion}

Analysis of the data given in table 2 shows that for all samples of fruiting bodies of mushrooms, the measured value of specific activity does not exceed the value of 2500 $\mathrm{Bq} / \mathrm{kg}$, established by sanitary norms and rules for dry mushrooms [15].

To discuss the obtained results, it is necessary to consider the specific activity data depending on the place of collection of the fruiting body. To determine the coefficient of variation of specific activity, the samples of fruiting bodies were divided into two groups depending on the place of collection. The first group - from 5228 to 5305 (Fig. 2., Table 2) - was collected on a plateau at the southern foot of the Poachvumchorr ridge. The second group - from 5334 to 5435 (Fig. 2., Table 2) - the collection was carried out between the trail and an unnamed stream, which originates in the Seytesyavr Lake and flows into the Maly Vudyavr Lake.

The variation in the specific activity of cesium-137 in the fruiting bodies of mushrooms is illustrated by the histograms in Fig. 3. For the samples of the first group, the coefficient of variation of specific activity (Table 2, Fig. 3A.) is $23.3 \%$, which characterizes the variability as significant. The significant variability of the specific activity for the fruiting bodies of mushrooms collected on the plateau near the southern slope of the Poachvumchorr ridge can be explained by a significant variation in the growing conditions of fruiting bodies and the thickness of the soil. Thus, some fruiting bodies were found on thin soil formed on closely spaced rocks, which, under dry conditions, caused a significant decrease in accumulation. The dry weather, in which the found fruiting bodies were formed, is evidenced by the cracking of the cap skin, which can be observed in photographs $5250,5255,5259,5271,5281,5283,5386$ (Fig. 2). For the samples of the second group, collected along the stream flowing from the Seytesyavr Lake, the coefficient of variation of specific activity (Table 2, Fig. 3B) is $14.6 \%$, which characterizes the variability as average.

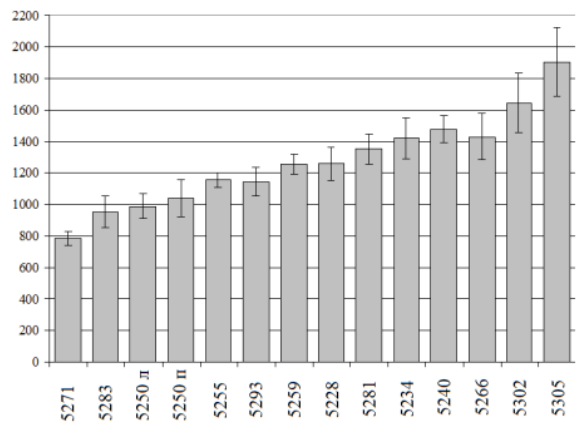

A. Plateau at the southern slope of Poachvumchorr

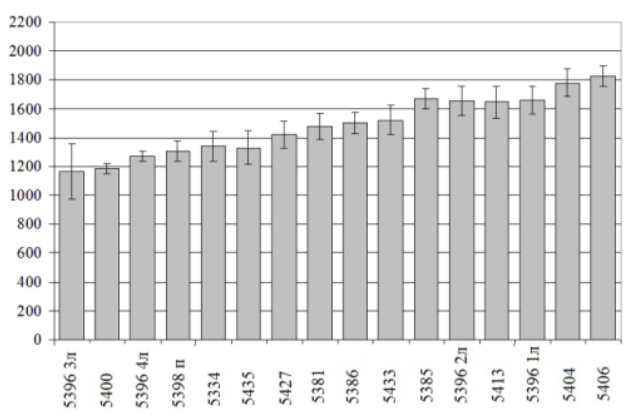

B. From the Seytesyavr Lake along the stream

Fig. 3. Variations in the specific activity of the studied samples. 
The data on specific activity obtained in this study are consistent with the data obtained for representatives of the genus Leccinum collected elsewhere [16, 17]. It is important to note that no excess of the permissible values of the specific activity of cesium-137 was recorded for all the studied samples of mushroom fruiting bodies.

Thus, the activity of cesium-137 of all studied samples is within acceptable limits and does not exceed $2500 \mathrm{~Bq} / \mathrm{kg}$, established for dry fruiting bodies of mushrooms. The obtained results can be used as reference values for comparison with the activity of fruiting bodies of mushrooms of the genus Leccinum, collected in other regions, if the activity exceeds the permissible values.

\section{Conclusions}

The paper contains original research results, which have not been previously published and are discussed with the involvement of both earlier authors' publications and those carried out on the study of the dynamics of cesium-137 in ecosystems and the taxonomy of this group of mushrooms.

\section{References}

1. L.A. Ilyin, V.A. Gubanov, Major radiation accidents: consequences and protective measures (M., "IzdAT",2001)

2. A. Vargasn, T.J. Yasunari, Atmospheric Chemistry Physics 12, 2313-2343 (2012)

3. Rosen K, Vinichuk M, Johanson K.J. Journal of Environmental Radioactivity 100(7), 534-539 (2009)

4. I. Amundsen, G. Gulden, P. Strand, Science of The Total Environment 184, 163-171 (1996)

5. C.L. Barnett, N.A. Beresford, P.L. Self et al., Science of The Total Environment 231, 67-83 (1999)

6. D.M. Ivanov, Vestnik of the St. Petersburg. University. Ser. 3. (Biology) 1, 90-95 (2013)

7. D.M. Ivanov Vestnik of the St. Petersburg University. Ser. 3. (Biology) 2, 30-35 (2013)

8. B.P. Vasilkov, Proceedings of Botanical Institute of the USSR Academy of Sciences II(10), 367 - 384 (1956)

9. Google Earth, https://earth.google.com/web/@67.67230099,33.63927216,470.26034077a,2423.84566 245d,35y,-4.7596382h,0.09232491t,0r

10. H.C. Den Bakker, B. Gravendeel, T.W. Kuyper, Mycologia 96(1), 102-118 (2004)

11. B.P. Vasilkov, Methods for accounting for edible mushrooms in the forests of the USSR (L., Nauka, 1968)

12. D.M. Ivanov, M.A. Efremova, Vestnink of the St. Petersburg University (Biology) 3, 52-59 (2012)

13. E.D. Ivanov, Materials of the IX International Ecological School-Conference in the Sergievka Estate - a monument of natural and cultural heritage: "Preservation of the natural environment and optimization of its use in the Baltic region" (St. Petersburg, VVM Publishing House, 2014) 
14. V.D. Ivanova, Proceedings of the XII Youth Ecological School-Conference in the Sergievka estate 2018: "Modern problems of natural and transformed ecosystems" (St. Petersburg, VVM Publishing House, 2018)

15. Hygienic requirements for safety and nutritional value of food products. Sanitary and epidemiological rules and standards SanPiN 2.3.2.1078-01. Approved by Chief State Sanitary Doctor of the Russian Federation on November 6, 2001, as amended on May 31, 2002, August 20, 2002, April 15, 2003

16. D.M. Ivanov, Actual problems of environmental management and environmental engineering: Collection of articles of the II International Scientific and Practical Conference (Penza, RIO PSAU, 2019)

17. E.D. Ivanov, Protection of biodiversity and environmental problems of nature management: Collection of articles of the All-Russian (national) scientific and practical conference (Penza, RIO PSAU, 2020) 